\title{
Frequency, Damage and Comparative Phonology of Annual Ground Cherry (Physalis divaricata L.) Weed in Sugar Beet Fields
}

\author{
Jamshid NAZARI ALAM, Hassan ALIZADE, Hmid RAHIMIAN MASHHADI \\ University of Tehran, Faculty of Natural and Agricultural Sciences, Iran; nazari.alam@gmail.com
}

\begin{abstract}
Ground cherry (Physalis divaricata L.) is one of the most important summer weeds in sugar beet crop in the west of Iran. In order to estimate the damage rate of this weed, field studies were conducted to quantify the effect of ground cherry density on sugar beet yield and to determine relationships among different weed densities $\left(0,0.5,1,2,4,8\right.$ and 16 plants $\left.\mathrm{m}^{-2}\right)$ and sugar beet yield in 2008 . The experiments were arranged in a randomized complete block design (RCBD) with four replications. In addition, the neighborhood effect of ground cherry was assessed in a completely randomized design. Neighborhood effect was surveyed from zero to $125 \mathrm{~cm}$ apart from each sugar beet plant to ground cherry. Density of ground cherry was estimated as the systematic method in 30 sugar beet fields that were chosen randomly.Phonology of ground cherry was recorded based on the GDD (Growth Degree Day) and date. Results showed that two weed plants $\mathrm{m}^{2}$ of this weed resulted in 34\% damage to sugar beet. Ground cherry significantly reduced yield of sugar beet when sown $50 \mathrm{~cm}$ apart from crop plant. Crop damage of sugar beet was $41 \%$ when ground cherry seeds were sown at zero $\mathrm{cm}$ apart from each sugar beet plant. Flowering of ground cherry occurred in the middle of June when it received 61.45-75 GDD and it proved that ground cherry is a neutralized weed to the long day.
\end{abstract}

Keywords: density, interference, growth degree day, neighbor effect

\section{Introduction}

Ground cherry is an annual dicotyledonous weed in the Solanaceae family and with a wide distribution in the west of Iran. It has long been regarded as one of the worst weeds of sugar beet. The similarity of germination time and growth habit between ground cherry and sugar beet makes it a difficult weed to control (Mousavi and Ahmadi, 2008). The amount of damage depends on environmental conditions, weed species, time of weed emergence, crop variety and crop density (Harker and Robert, 2007). Among crops, sugar beet is one of the most sensitive plants to weed interference (Williams, 2006). In general, the existence of an annual weed in sugar beet (one plant per square meter) causes more than 20 percent sugar beet yield loss (Kuchinda, 2001). However, the amount of damage due to weed is different depending on the weather conditions in each year. In order to achieve weed management, the prediction of weather and its changes is required (Pattrick et al., 2003).

The neighborhood effect is defined as the effect of adjacent plants on a single plant. A plant cannot relocate from an unfavorable location to a more favorable one. Rather, it grows as well as possible where it finds itself or it dies. Basic plant biology suggests that plant interactions are inherently local in nature. For example, individual plants do not experience global population density per se, but only interact with neighbor over restricted distances (Buckelew et al., 2006). Negative neighbor effects are usually more important than positive ones, because all plants require basically the same resources. If plants are growing in close proximity, it seems almost inevitable that they will eventually compete for some of these resources. It is important to distinguish between the effects an individual plant has on resources and how that plant responds to the preemption of resources by its neighbors (Goldberg, 1990). Thus, the intensity of competition is determined by two processes: (1) the effects of neighbors on resource availability and (2) the ability of individuals to tolerate or compensate for these effects through plasticity and other "behavioral" responses (Hrig and Tzel, 2001). Neighborhood effects have often been evaluated from regressions of individual plant performance, such as size or growth, on neighborhood indices, which represent the condition of the neighborhood based on distance, size, species and or spatial arrangement of neighbors (Mead, 1996). Large individuals obtain a disproportionate share of resources relative to smaller individuals (Weiner and Thomas, 1986). Thus, the effects of neighbors smaller than a focal plant in such indices should be discounted depending on the degree of competitive asymmetry (Thomas and Weiner, 1989). The ground cherry has huge canopy and affects the growth and development of crops. Thus it seems necessary to determine the effect of this plant on crops especially sugar beet.

Plants vary widely in their growth and phonological behavior such differences can be attributed partly to innate species traits (Hegazya et al., 2005). Many studies have demonstrated the plant attributes explaining growth 
130

and phonology, variation, such as physiology, morphology, anatomy and competition (Grime and Hunt, 1975). Phonology depends on temperature, photoperiod and competition (Swanton and Murphy, 1996). Plant development depends on temperature. Plants require a specific amount of heat to develop from one point in their life cycle to another, such as from seeding to the four-leaf stage (Fidanza et al., 1996). People often use a calendar to predict plant development for management decisions. However, calendar days can be misleading, especially for early crop growth stages. Though temperatures often average out from year to year over an entire growing season, there are usually cooler- or warmer-than normal times during significant parts of the growing season. As the saying goes, "normal" weather is an average of extremes. Warmer-than normal days advance the plant and insect growth rapidly, while cooler than- normal days slow them. "Growing degree days" (abbreviated GDD or DD) is a way of assigning a heat value to each day. The values are added together to give an estimate of the amount of seasonal growth your plants have achieved (Elmore, 1996). Phonological studies provide information on functional rhythms of plants and plant communities, where various phonological events may be timed to biotic and/or abiotic environmental conditions (Estabrook et al., 1982). Phonological studies provide information on functional rhythms of plants and plant communities (Ralhan et al., 1985), where various phonological events may be timed to biotic and/or abiotic environmental conditions (Estabrook et al., 1982). The success of weed management programs that are based on ecological principles and weed biology depends largely upon a better understanding of how environmental factors affect life history traits, growth and competitive interactions of crops and weeds, and particularly upon the ability to predict crop and weed phonology (Ghersa and Holt, 1995). Phenological predictions would allow more accurate estimates of the timing and effects of weed competition on crop yield in particular agronomic systems and thus allowing more specific control measures to be developed (Alm et al., 1991).

Ground cherry is one of the most common and most important summer weeds in the west of Iran. Most studies on this species are focused on its medical effects, usage and extraction of medical active substance (Lei et al., 2007) and there is not any significant research on the biology and damage of this weed on any crop (Mousavi and Ahmadi, 2009). Every year, new farms are infected by the ground cherry. The success of weed management programs that are based on ecological principles and weed biology depends largely upon a better understanding of how environmental factors affect life history traits, growth and competitive interactions of crops and weeds, and particularly upon the ability to predict crop and weed phonology.

The objective of this study is to demonstrate the assessment and estimation of competition, neighboring and evaluate phonological behavior of ground cherry weed species in relation to sugar beet crops in order to achieve better management of this weed in the west of Iran.

\section{Materials and methods}

\section{Damage, neighbor effect and density}

Field experiments were conducted in 2007-2008 in the west of Iran, Lorestan province, $\left(35^{\circ} 52^{\prime} \mathrm{N}\right.$ latitude, $48^{\circ} 12^{\prime}$ E longitude and altitudes of $1580 \mathrm{~m})$. The research field had a clay loam soil. Experimental sites were moldboardplowed in the fall, disked in early April, fertilized according to soil-test recommendations, and cultivated before planting and seeded on April sugar beet cultivar, 'Monogerm'. The distance between plant rows was $50 \mathrm{~cm}$ and plant density was 9 plants per square meter at sowing time. Seven weed density treatments were established: $0,0.5,1,2$, 4, 8 and 16 ground cherry plants $\mathrm{m}^{-2}$. Experimental sites were kept free of weeds other than ground cherry by hand weeding. The experiments were arranged in a randomized complete block design (RCBD) with four replications. The blocks were $1 \mathrm{~m}$ apart each other and there was 0.5 $\mathrm{m}$ distance between treatments. The ground cherry seeds were sown near the sugar beet plants on the rows in high density and after seed germination they were thinned to desirable density. The plots were $5 \mathrm{~m}$ long and consisted of 4 rows, $0.5 \mathrm{~m}$ apart from next row. In each plots other weeds were removed by hand. Plots were irrigated twice in month. The crop was harvested in early of October of 2008 and yield of sugar beet was calculated in per square meter of per plot and the sugar beet was calculated in per square meter of per plot.

To determine the neighbor effect of ground cherry on single beet plant the neighboring effects method (Berger and Hilden, 2000) is used. Four rows of sugar beet which were reasonably equal (same density) were selected. On each row, ground cherry seeds were sown apart from sugar beet plants. The distances between sugar beet seeds and ground cherry seeds were $0,50,70,100$ and $125 \mathrm{~cm}$. Since sugar beet has high genetic variation and in terms of the response to the environment, the same and equal rows were selected for ground cherry cultivation. The neighbor effect was evaluated in a completely randomized design with four replications because of short rows and soil properties didn't have significant effect on results. After emergence, all the weeds (except single-plant of ground cherry) in the rows were removed. Irrigation was done every two weeks during the growing season. In early October of 2008, in order to estimate the effect of ground cherry on sugar beet yield, sugar beet single plants were harvested from 0 to $125 \mathrm{~cm}$ distance and yield was estimated.

To estimate density and type of weeds in sugar beet fields in Lorestan region, in the second half of September, before harvest, 30 sugar beet fields were selected randomly. From each field, 5 samples (each sample was one square meter) underwent systematic sampling. Thus, 150 samples were collected from different parts of the region to deter- 
mine the density and type of weeds. In addition the density of ground cherry, density and type of other weeds were identified in the region.

\section{Phonology}

To evaluate ground cherry phonology, in early April after sugar beet cultivation, two fields were selected randomly. In each field four fixed quadrates were placed and then allowed to just one ground cherry to grow near the sugar beet. Therefore, the phonology of eight plants was evaluated in two different fields. From the emergence time to harvest crop, developmental stages of weed and sugar beet were recorded every week in a time period of 20 weeks. Observations on phonology were carried out using the phonological index technique (West and Wein, 1971; Hegazy and Eesa, 1991). According to this technique numerical ratings were given to six defined phenol phases, $1=$ seedling, $2=$ =juvenile, $3=$ flower bud, $4=$ flowering, $5=$ fruiting, and $6=$ seed dispersal. Each of the studied eight weeds was observed monthly in two fields (Adrien $e t$ al., 2001. Snedecor and Cochran, 1967). Data (day and night temperature from April to October) was taken from weather station. The station was located three kilometers away from site of study. Using recorded meteorological data and registered growth stages date, amount of required temperature for pass of each phonology stages were calculated on the base of growing degree days (GDD).

\section{Result and discussion}

\section{Density, damage and neighbor effect}

Many of broad-leaf weeds appear in sugar beet fields of the west of Iran (Tab. 1). Among the broad-leaf weeds, the ground cherry has the highest density. The density of this weed was 2.05 plants $\mathrm{m}^{-2}$ in sugar beet fields in the west of Iran (Tab. 1). In some fields, the density was 8 plants $\mathrm{m}^{-2}$. Among 30 sampled filed; only two fields were ground cherry-free, thus the frequency of this weed was $93 \%$ according to the formula below. Frequency $=$ all sampled fields/infected fields. This result showed the high prevalence of this weed in sugar beet fields.

Yield percent of sugar beet in different weed densities using reciprocal fitted is shown in Fig. 1 (Hrig and Tzel, 2001). $Y=1 /\left(0.0101+0.0027^{*} N_{w}\right)$. Whereas; $Y=$ crop

Tab. 1. Density of different weeds (plant $\mathrm{m}^{-2}$ ) in sugar beet crops in the west of Iran

\begin{tabular}{ccc}
\hline Row & Scientific name & Density $\left(\right.$ plant $\left.\mathrm{m}^{-2}\right)$ \\
\hline 1 & Physalis divaricata & 2.05 \\
2 & Hibiscus sp. & 1.67 \\
3 & Convolvolus arvensis & 1.36 \\
4 & Sorghum halpens & 0.87 \\
5 & Setaria viridis & 0.75 \\
6 & Chenopodium album & 0.49 \\
7 & Amaranthus sp. & 0.45 \\
8 & Portulaca oleracea & 0.24 \\
\hline
\end{tabular}

yield; $N_{w}=$ number of weed in square meter; $\mathrm{R}^{2}$ is Correlation coefficient that shows the direct and significant relationship between yield and number of weeds per square meter. The correlation coefficient in this study was $99 \%$. In other words, the increase of weed number is equal to yield reduction. Referring to this equation, the yield and weed number have a reverse relation. It was shown that the higher the ground cherry number per square meter, the lower sugar beet yield. According to the results of this study, final yield was decreased by $81 \%$ compared to control when weed density was increased from 0 plants to 16 plants per square meter (Tab. 1). The density of weeds in sugar beet fields was 2.9 plants per square meter. Results showed that 2.9 (plants $\mathrm{m}^{-2}$ ) of this weed, decreased sugar beet yield by $43 \%$ in comparison to the control. In addition, one weed (plant $\mathrm{m}^{-2}$ ) decreased sugar beet yield by $23 \%$.

The present results are approved by the results of Harcker (2007) who showed one plant $/ \mathrm{m}^{-2}$ decreases final yield with about $20 \% .8$ plants $/ \mathrm{m}^{-2}$ decreased sugar beet yield by $70 \%$ (Fig. 1). In some fields, the density of ground cherry was about eight plants per square meter, thus according to additional series design it can be predictable that the damage rate is equivalent to 70 percent so that it is very noticeable. At low weed density, the percentage of yield loss had a steep slope while the increase of weed density led to a gentle slope (Fig. 1). The reason for this is that at higher weed densities, weed plants also compete with each other due to such spatial effects of weed competition, thus they tend to neutralize each other. This intra-competition causes the gentle slope in competition curve parallel with the increase of weed number per square meter (Berger and Hildenbrandt, 2000). Therefore, the percentage of damage is similar at higher densities (Fig. 1). The comparison of means by LSD test showed that there wasn't any significant difference between 0.5 and 1 weed per square meter. In addition there wasn't a significant difference between 8 and 16 weed per square meter on final yield (Tab. 2) while there was significant difference between 1, 2 and 4 weed per square meter treatments. Also there was significant difference between 0.5 weed per square meter in comparison to control (weed-free treatment) so that yield was decreased by $19 \%$ in this treatment.

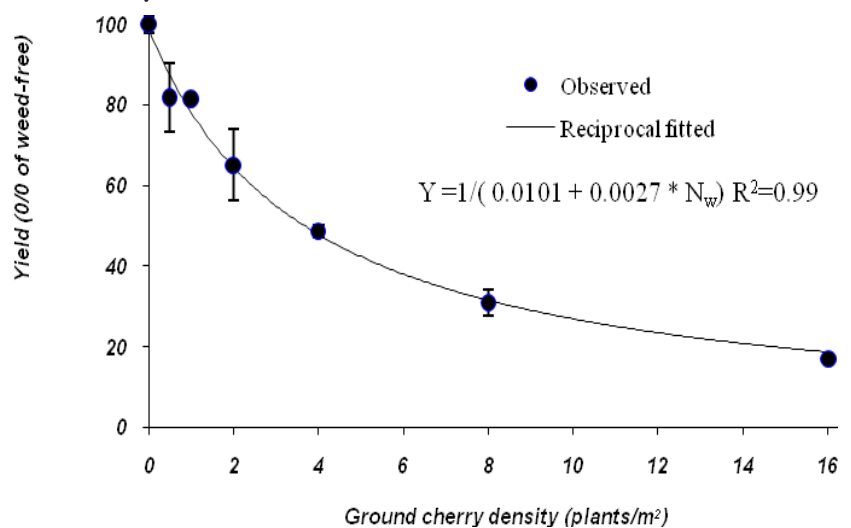

Fig. 1. Effects of weed density of ground cherry on sugar beet yield 
132

Tab. 2. Sugar beet yield affected by different density of ground cherry weed

\begin{tabular}{cc}
\hline Weed density $\left(\right.$ plant $\left./ \mathrm{m}^{2}\right)$ & Yield $(\mathrm{t} / \mathrm{ha})$ \\
\hline 0 & $52.08 \mathrm{a}$ \\
0.5 & $41.82 \mathrm{~b}$ \\
1 & $41.08 \mathrm{~b}$ \\
2 & $33.05 \mathrm{c}$ \\
4 & $24.83 \mathrm{~d}$ \\
8 & $15.83 \mathrm{e}$ \\
16 & $8.750 \mathrm{e}$ \\
\hline
\end{tabular}

Note: Different letters between means denote significant differences (LSD test, $\mathrm{P}<0.05)$

Neighbor effect was estimated using exponential rise equation (Bergerand and Hildenbrandt, 2000). $\mathrm{Y}=348.17+255.09^{*}\left(1-\exp \left(-0.032^{*} \mathrm{x}\right)\right)$ Whereas $\mathrm{Y}=$ single plant yield; $\mathrm{x}=$ distance from weed. In this equation, the number 348 means yield of sugar beet $(\mathrm{g})$ per plant at the nearest distance (zero $\mathrm{cm}$ ) from the ground cherry (Fig. 2). Although ground cherry affected sugar beet when $100 \mathrm{~cm}$ far from plants, it was not significant. When this distance was decreased to $50 \mathrm{~cm}$ the results became statistically significant . The average sugar beet yield (g/plant) was 557 when they were apart from weeds by $50 \mathrm{~cm}$ (Fig. 2). Average sugar beet yield per plant was more than 600 grams by $125 \mathrm{~cm}$ distance from single plants of this weed. At the closest distance between the weeds and sugar beet (zero $\mathrm{cm}$ ), the amount of damages to the sugar beet was 41.7 percent (Fig. 3). The ground cherry had little effect when it was sown far from sugar beet plants 50 to $100 \mathrm{~cm}$, while there was no effect at $100 \mathrm{~cm}$ distance. Estimated line in Figure 3 was tangent on the horizontal axis (distance between sugar beet and ground cherry) from this point forward (form $100 \mathrm{~cm}$ to forward) percent of damage was zero. According to Kuchinda's (2001) report, the neighbor effect is related to plant size and distance between two plants. A single plant of this weed is much larger than those plants which have grown at high density so they are

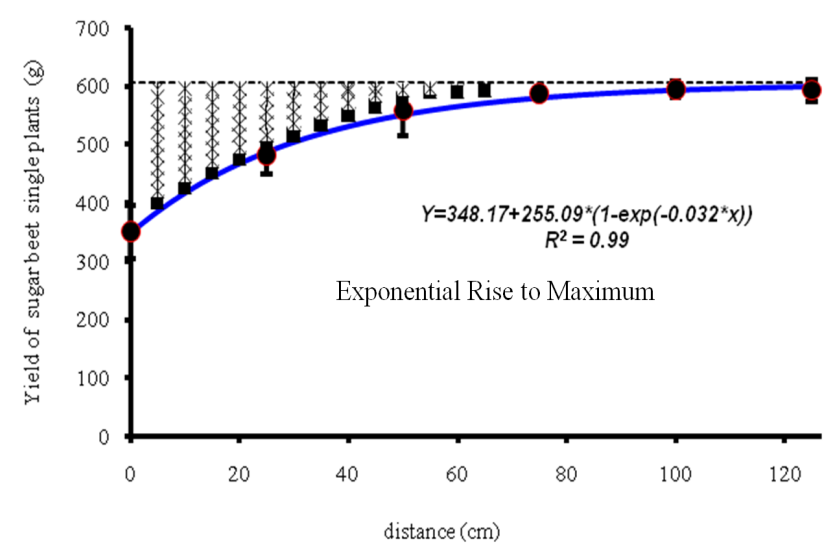

Fig. 2. Neighbor effect of ground cherry upon yield of sugar, the higher the sugar beet distance from single weed, the higher the yield

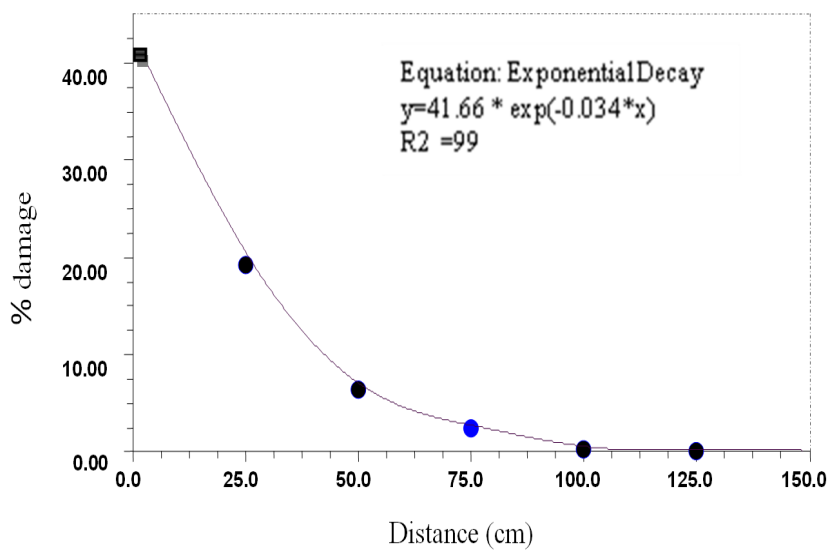

Fig. 3. Percent of damage in the single sugar beet in the neighbor of ground cherry weed

able to affect on adjacent plants. Sugar beet yield was safe when ground cherry seeds were sown at $100 \mathrm{~cm}$, in other words there wasn't any reduction in yield (Fig. 2). Due to the large and spread canopy of this weed, competitiveness characteristic of this weed is reasonable in long distances. Effect of ground cherry on adjacent plants is more dependent on the huge canopy than underground parts.

\section{Phonology based on GDD}

Ground cherry germination was initiated on $25^{\text {th }}$ April (Fig. 4). Base temperature for ground cherry is under $14.5^{\circ} \mathrm{C}$ (Mousavi and Ahmadi, 2008). After entering 49.8 to 55 GDD, it entered fast growth and development of leaf stages in the middle of May (stage II). This stage took around one month from the second half of May to the second half of June. Flowering was initiated in the middle of June after receiving 61.45 - 75 GDD (stage III). Fruits were set in the middle of July by receiving 186.3-199.4 GDD (stage IV). Also berries were formed after receiving 186.3-199.4 GDD and after 4 weeks the seeds were ripened when the plants caught 314.65-325 GDD. Seed distribution initiated in the middle of August (454.14 GDD, stage V). As mentioned above, germination and leaf development period was long in this weed. Alm et al. (1991) has reported that high relative growth and fast leaf production help plants in competition with other plants. It's possible that the increase of this period is due to the increase of competitiveness effect to achieve dominance with other plants. The process of flowering, fruit and seed distribution was initiated from the second half of June and continued until the middle of October (Fig. 4). The longterm flower and fruit production, and it continuation until the end of season shows that ground cheery and many such weeds have special potential in seed production (Alm et al., 1991). Also flower production during the growing season (from June to October), has supplied its survival, because at any time of the season, this plant is capable to produce flowers This represents that the ground cherry is a non-sensitive weed to the length of days. Study on comparative phonology of the weed with sugar beet showed 


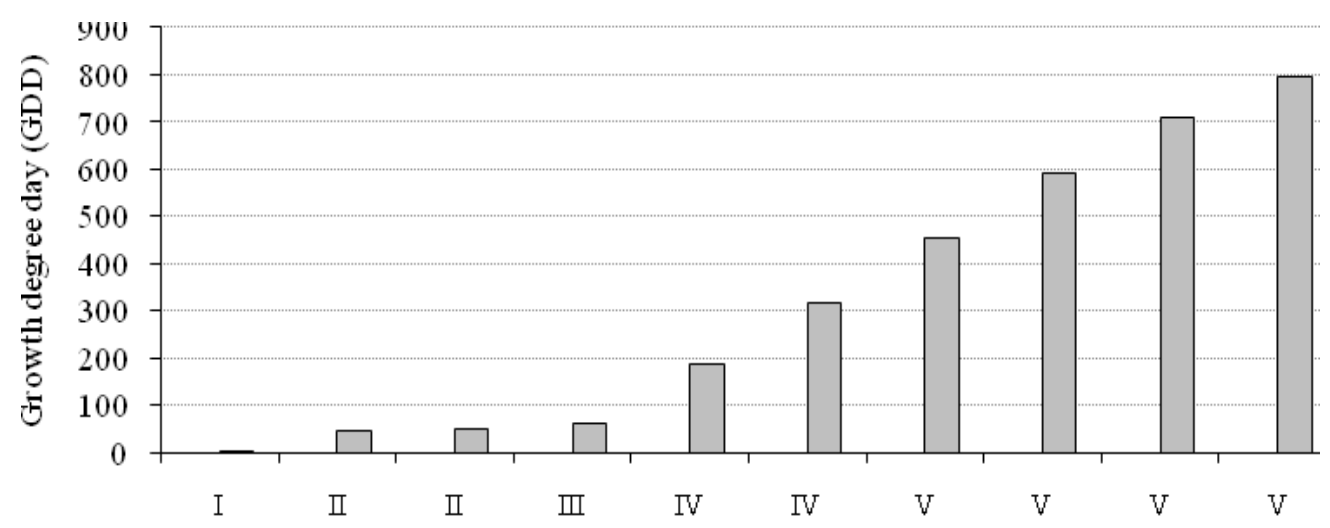

Fig. 4. Growth stages of ground cherry based on the growth index; I=Seedling; II=Juvenile; III= Flower bud-flowering; IV= Flower bud-flowering-fruiting; V= Flower bud-flowering-Fruiting -Seed disperse

that, in the early stages of growth, sugar beet entered into two and three leafy stages earlier than the ground cherry (Tab. 3). Sugar beet was sown in early spring (April) and berries were set. Abscission of berries started during the first half of August. However, most berries remained until the end of the growth season (Tab. 3).

Tab. 3. Phonological ground cherry weed on the base of GDD and growth index in comparison to sugar beet crop. $(1=$ seedling. $2=$ juvenile. 3 = flower bud. $4=$ flowering. $5=$ fruiting. $6=$ seed disperse)

\begin{tabular}{|c|c|c|c|c|}
\hline Date & $\mathrm{GDD}^{1}$ & Growth stage of sugar beet & Growth stage of ground cherry & Growth index \\
\hline First half May & 2 & Cotyledon-two real leafs & Seedling & 1 \\
\hline Second half May & 43.7 & 3 and 4 real leafs & Juvenile & 2 \\
\hline First half Jun. & $49.8-55$ & 5 and 6 real leafs & Juvenile & 2 \\
\hline Second half Jun. & $61.45-75$ & 9 and 10 real leafs & Flower bud-flowering & $3-4$ \\
\hline First half Jul. & $186.3-199.5$ & 13 and 14 real leafs & Flower bud-flowering-fruiting & $3-4-5$ \\
\hline Second half Jul. & $314.65-325$ & 14 and 15 real leafs & Flower bud-flowering-fruiting & $3-4-5$ \\
\hline First half Aug. & 454.15 & 15 and 16 real leafs & Flower bud-flowering-Fruiting -Seed disperse & $3-4-5-6$ \\
\hline Second half Aug. & 589.95 & 15 and 16 real leafs & Flower bud-flowering-Fruiting -Seed disperse & $3-4-5-6$ \\
\hline First half Sept. & 708.45 & 15 and 16 real leafs & Flower bud-flowering-Fruiting -Seed disperse & $3-4-5-6$ \\
\hline Second half Sept. & 795.95 & 15 and 16 real leafs & Flower bud-flowering-Fruiting -Seed disperse & $3-4-5-6$ \\
\hline First half Oct. & - & 15 and 16 real leafs & Flower bud-flowering-Fruiting -Seed disperse & $3-4-5-6$ \\
\hline Second half Oct. & - & & Dead & \\
\hline
\end{tabular}

germination occurred before weed emergence, but according to slow growth of sugar beet, this crop was not able to pass the growth stages like the ground cherry (Tab. 3 ). Sugar beet in the first (stage 2 of phonological stage) with high leaf area and spread canopy, hence it can be expected that the weed overcomes the crop and reduces final yield (Bazzaz, 1990). At the second half of half of June, at 49.855 growing degree days, it entered into 5 to 6 leafy stage, while the ground cherry at the same time received the same degree-day growth and entered into seedling stage. June ground cherry entered into flowering stage (3-4 leafy stage) and at this time sugar beet just had 9 or 10 expanded leaves (Tab 3). In order for this weed to pass the flowering stage and enter to fruit set stage, it needed high GDD and it can helps to plant to product more flowers. This is one of the most important strategies that can help the weed to produce more seeds. In fact, before berry production, ground cherry produced a lot of leaves and branches and following numerous flowers. One week after flowering,

\section{Conclusions}

The ground cherry is one of the most important summery weeds in sugar beet production in the west of Iran. In some fields the density of the ground cherry was very abundant. Thus, it can causes a lot of damage, at a rate of even 70 percent. So that it is very noticeable. Single ground cherry had a significant effect on sugar beet from $50 \mathrm{~cm}$ distance but to $100 \mathrm{~cm}$ distance fdidn't exert any significant effect. After receive some of GDD, this weed entered fast growth and development of its leaves. Flower production during the total growing season, (from June to October), showed that this plant is capable of producing flowers at any time of the season and this showed that the ground cherry is a non-sensitive weed to length of days. Thus, one of the best strategies of this weed is to be neutralized to the length of day, in terms of development and ovulation in fields but plants of this weed that enter flowering in late season, demolish because of autumn cold. 
134

\section{Acknowledgements}

This research was funded by the Department and Faculty of Natural and Agricultural Sciences, University of Tehran.

\section{References}

Alm D, Giffen J, Hesketh J (1991). Weed phonology. In: Hodges, Predicting Corp Phonology. CRC Press Boca Raton FL, p. 91-218.

Bazzaz F (1990). Plant-plant interactions in successional environments. In Perspectives. Tetrahedron Letters 48:449452.

Berger U, Hildenbrandt H (2000). A new approach to spatially explicit modelling of forest dynamics: spacing, ageing and neighbourhood competition of mangrove trees. Ecology 132:287-302.

Buckelew J, Monks D, Hoyt G, Walls R (2006). Effect of eastern black nightshade (Solanum ptycanthum) on transplanted plasticulture tomato grade and yield. Weed Sci 54:504-508.

Elmore C (1996). A reintroduction to integrated weed management. Weed Sci 44:409-412.

Estabrook GF, Winsor JA, Stephenson AG, Howe HF (1982). When are two phenological patterns different? Botanical Gazette 143:374-378.

Fidanza M, Dernoeden P, Zang M (1996). Degree-days for predicting smooth crabgrass emergence in cool-season turf grasses. Crop Sci 36:990-996.

Goldberg DE, Werner PA (1983). Equivalence of competitors in plant communities: A null hypothesis and a field experimental approach. American Journal of Botany 70:1098-1104.

Ghersa CM, Holt JS (1995). Using phonology prediction in weed management: a review. Weed Res 35:461-470.

Grime JP, Hunt R (1975). Relative growth rate: its range and adaptive significance in a local flora. Journal of Ecology 63: 393-422.

Harker K, Robert E (2007). Wild Oat (Avena fatua) vs. Redstem Filaree (Erodium cicutarium ) Interference in Dry Pea. Weed Tec 21:235-240.

Hegazy A (2001). Reproductive diversity and survival of the potential annual Diplotaxis harra (Forssk.) Boiss (Brassicaceae) in Egypt. Ecography 24:403-412.

Hegazya A, Fahmya G, Alia N (2005). Growth and phonology of eight common weed species. J Arid Environ 61:71-183.
Hrig M, Tzel H (2001). A model for light competition between vegeTab crops and weeds. European J Agron 14:13-29

Kuchinda N (2001). The ejects of nitrogen and period of weed interference on the bre yield of kenaf (Hisbiscus cannabinus L.) in the northern Guinea Savanna of Nigeria. Crop Pro 20:229-235

Lei M, Mohammad A, Li-Hong H (2007). Withaphysanolide A, a novel C-27 norwithanolide skeleton, and other cytotoxic compounds from Physalis divericata L., p. 239-263. In: Grace JB and Tilman D (Eds.). Plant Competition.

Mousavi S, Ahmadi A, (2008). Effect of environmental conditions on germination of Ground cherry (Physalis divaricata L.) Journal of Plant Pathol 76:10-30.

Mead R (1966). A relationship between individual plant-spacing and yield. Annals of Botany 30:301-309.

Patrick J, Tranela M, (2003). Variation in soybean (Glycine $\max ($ L.) Merr.) interference among common cocklebur (Xanthium strumarium L.) accessions. Crop Pro 22:375380.

Ralhan PK, Khanna RK, Singh SP, Singh JS (1985). Phenological characteristics of the tree layer of Kumaun Himalayan forests. Vegetation 60:91-101.

Swanton CJ, Murphy SD (1996). Weed science beyond the weeds: the role of integrated weed management (IWM) in agro ecosystem health. Weed Sci 44:437-445.

Snedecor GW, Cochran WG (1967). Statistical Methods, sixth Ed. Iowa State College Press, Iowa.

Thomas SC, Weiner J (1989). Including competitive asymmetry in measures of local interference in plant populations. Oecologia 80:349-355.

Tworkoski T (1992). Developmental and environmental effects on assimilate partitioning in Canada thistle (Cirsium arvense). Weed Sci 40:79-85.

Williams D (2006). Functional relationships between giant ragweed (Ambrosia trifida) interference and sweet corn yield and ear traits. Weed Sci 54:948-953.

West NE, Wein RW (1971). A plant phenological index technique. Bio Science 21:116-117. 